\title{
LA-UR-19-28494
}

Approved for public release; distribution is unlimited.

Title: $\quad$ A New Organometallic Americium Complex

Author(s): $\quad$ Gaunt, Andrew James

Intended for: $\quad$ Science Highlight for external web.

Issued: 2019-08-22 
Disclaimer:

Los Alamos National Laboratory, an affirmative action/equal opportunity employer, is operated by Triad National Security, LLC for the National Nuclear Security Administration of U.S. Department of Energy under contract 89233218CNA000001. By approving this article, the publisher recognizes that the U.S. Government retains nonexclusive, royalty-free license to publish or reproduce the published form of this contribution, or to allow others to do so, for U.S. Government purposes. Los Alamos National Laboratory requests that the publisher identify this article as work performed under the auspices of the U.S. Department of Energy. Los Alamos National Laboratory strongly supports academic freedom and a researcher's right to publish; as an institution, however, the Laboratory does not endorse the viewpoint of a publication or guarantee its technical correctness. 


\section{A New Organometallic Americium Complex}

Scientists from Los Alamos, Prof. W. J. Evans at UC-Irvine, and their collaborators, have synthesized and gathered the first structural data on an organometallic cyclopentadienyl (Cp) complex of americium (Am). Americium is an important element that is of interest for reasons such as nuclear energy research and waste disposal, however it is challenging to work with because it is both scarce and highly radioactive. Historically, americium was viewed as sitting at an intersection in actinide chemistry where the elements begin to behave more "lanthanidelike". Thanks in part to recent work at Los Alamos and others, this simplistic picture is being reimaged with a more nuanced and detailed comprehension of how americium subtly differs from other actinides and lanthanides. The research was published in the international chemistry journal Angewandte Chemie.

The work included small-scale optimization that was performed on lanthanide and actinide analogues and that allowed the scientists to successfully work with only $5 \mathrm{mg}$ of Americium. Their high product yield allowed a suite of analytical data to be gathered that is often absent with transuranium molecular characterization. In the paper, they describe experimentally confirmed theoretical predictions about actinide $\mathrm{f}$ - and d-orbital energies and bonding as the actinide series is traversed to Am. X-ray characterization comprised the first metrical quantification of an americium-carbon molecular bonding interaction. The metal- $(\mathrm{Cp})_{n}$ motif is a cornerstone of organometallic chemistry across the periodic table, and their work begins to define subtle bonding and electronic changes in homologous f-element molecules into the rarely studied realm beyond plutonium, providing important benchmark data and direct comparisons.

Cutting-edge basic research into americium maintains high visibility for LANL and the LDRD program in the broader academic chemistry community, ensuring the Institution's reputation as a world leader in multiple aspects of actinide science. The work also advances the goals of the DOE-SC, Basic Energy Sciences, Heavy Element Chemistry program, which has basic research needs for understanding the role of the $5 f$-electrons in compounds and elucidating the chemical bonding of the actinide elements. Los Alamos is rare in our ability to perform both applied and fundamental research on the highly radioactive transuranic elements of neptunium, plutonium, and americium. Discoveries such as the one described here offer new insights that improves understanding of the basic chemistry of americium; knowledge of these basic principles has future potential to be controlled and manipulated in areas such as developing new processes and waste disposition/remediation strategies in the nuclear fuel cycle and environment.

This molecular synthesis and a number of characterization data was funded by LDRD ( Exploratory Research and Postdoctoral Fellowship Program. Additional aspects were funded from other DOE sources as detailed in the manuscript. Ref: Angew. Chem. Int. Ed. 2019, 58, 11695-11699. DOI: 201905225. Authors: Conrad Goodwin, Andrew Gaunt, Stosh Kozimor, (LANL Chemistry Division) Jing Su, Enrique Batista, Ping Yang (LANL Theoretical Division), Brian Scott (LANL MPA Division), Thomas Schmitt (Florida State), Anastasia Blake (LANL Chemistry Division/Univ. of lowa), Scott Daly (Univ. of lowa), Stefanie Dehnen (Marburg), Niels Lichtenberger (LANL Chemistry Division/Marburg), William J. Evans (UC Irvine). 


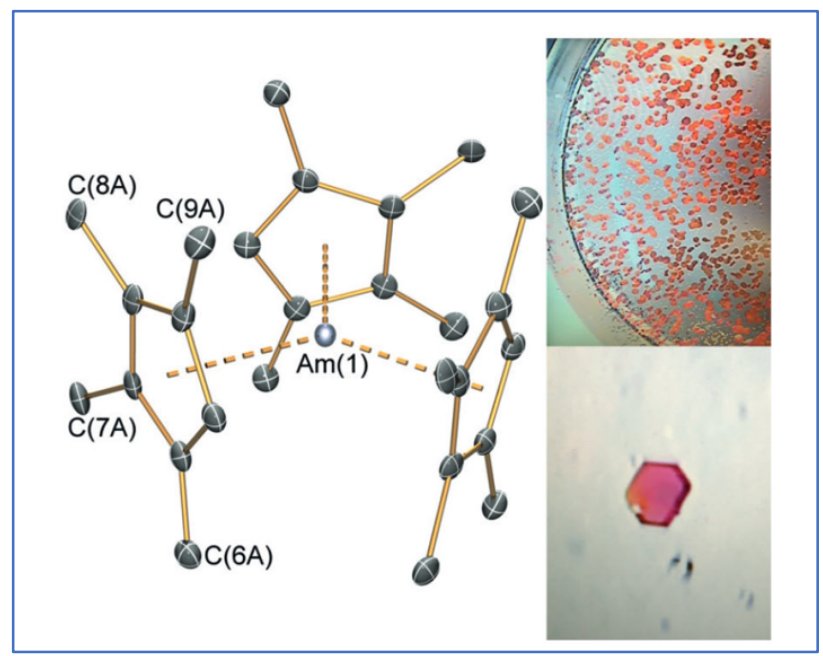

Figure 1: Left: Molecular structure of the americium complex studied. Right: Crystals grown to help determine the structure of the molecule.

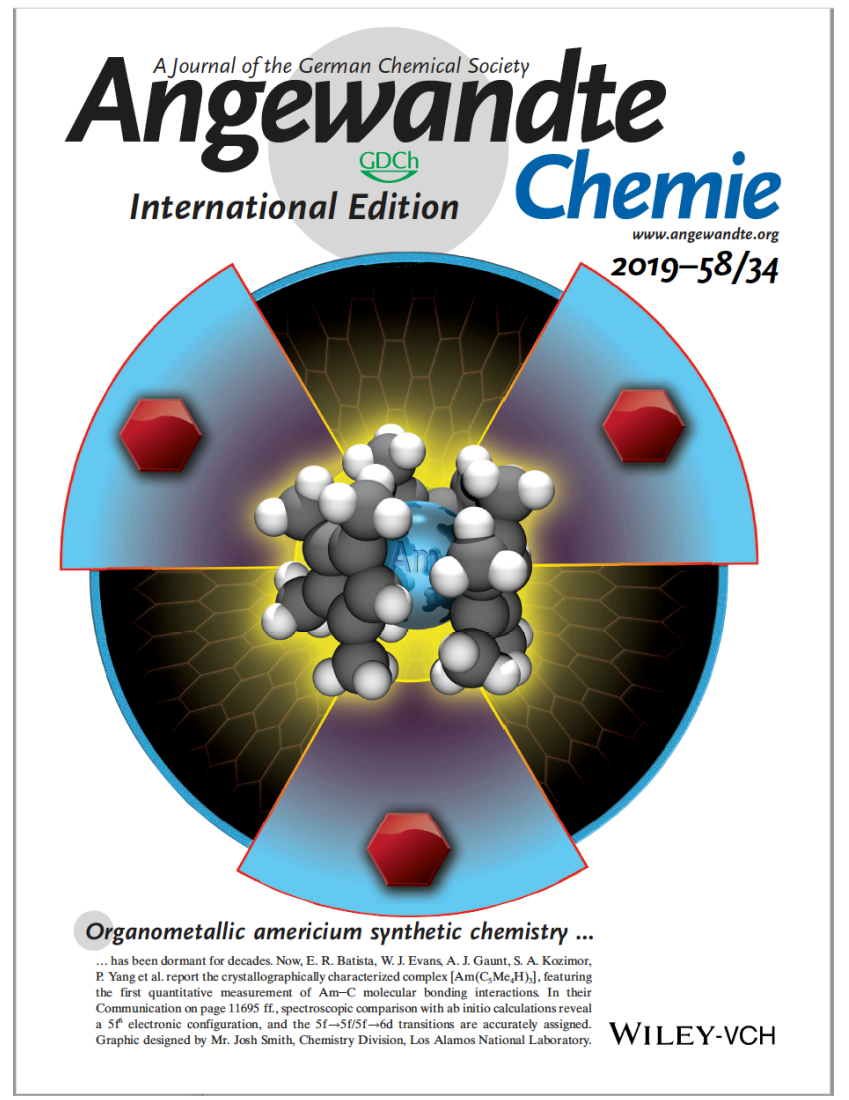

Figure 2: This research was featured on the back cover of the journal. The americium complex is shown, with the Am-C bonds highlighted in the structure. 